Supporting Information

\title{
BTEX Vapors Detection with a Flexible MOF and Functional Polymer by Means of a Composite Photonic Crystal
}

\author{
Donghui Kou, ${ }^{\dagger}$ Wei Ma, ${ }^{* \dagger}$ Shufen Zhang, ${ }^{\dagger}$ Rui Li ${ }^{\ddagger}$ and Yi Zhang* \\ †State Key Laboratory of Fine Chemicals, Dalian University of Technology, Dalian, \\ Liaoning 116023, PR China \\ \$School of Physics, Dalian University of Technology, Dalian, Liaoning 116023, PR \\ China \\ *Corresponding author: E-mail: weima@dlut.edu.cn
}



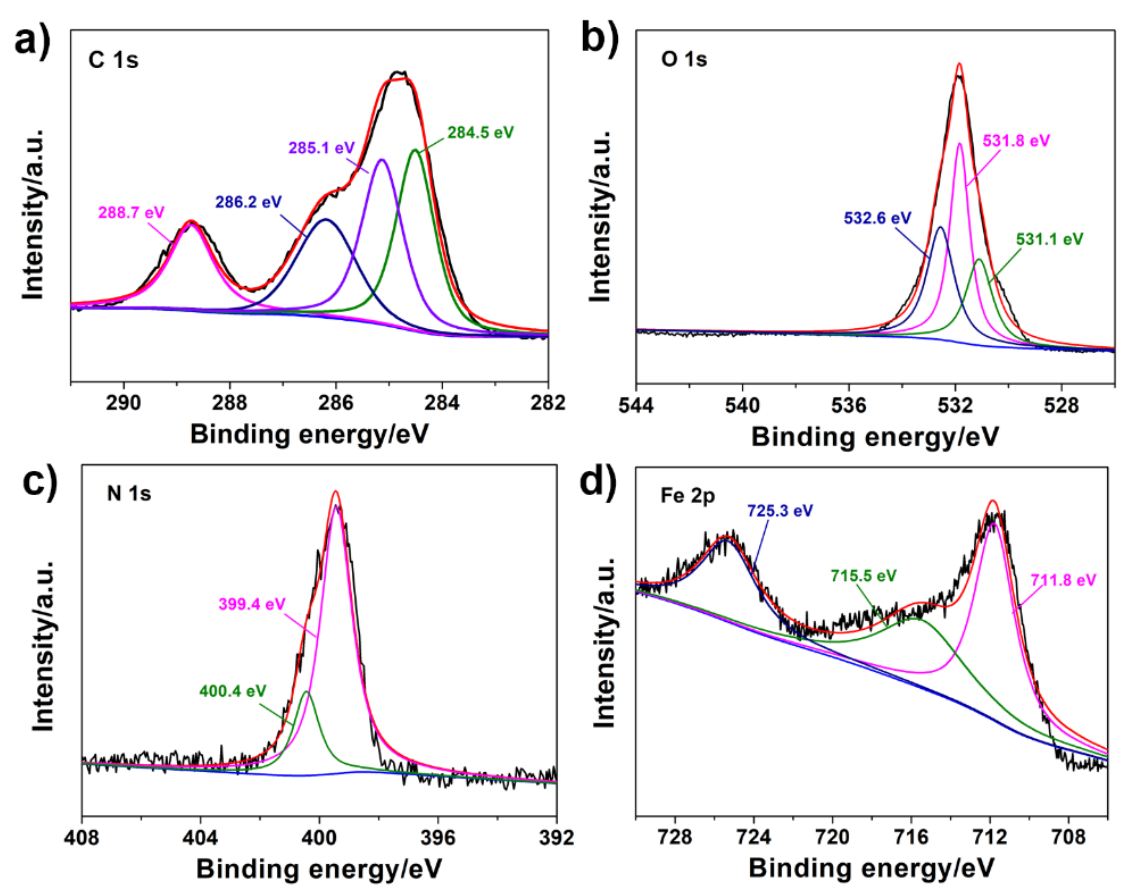

Figure S1. High resolution XPS spectra of $\mathrm{NH}_{2}-\mathrm{MIL}-88 \mathrm{~B}(\mathrm{Fe})$ : a) C 1s; b) O 1s; c) N 1s; d) Fe 2p.

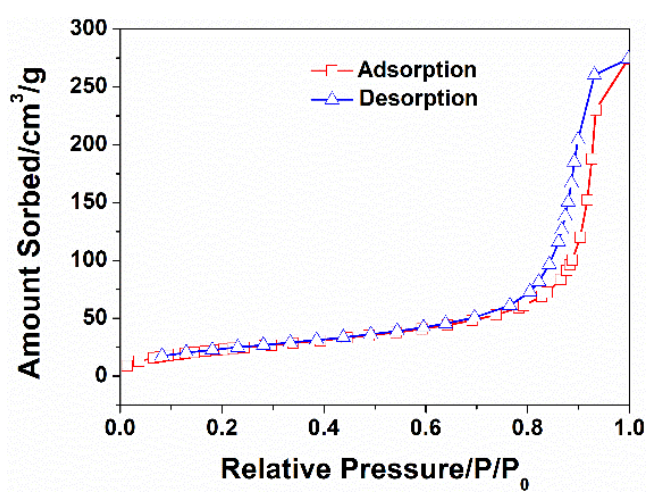

Figure S2. $\mathrm{N}_{2}$ sorption/desorption isotherms of the as-synthesized $\mathrm{NH}_{2}-\mathrm{MIL}-88 \mathrm{~B}$.

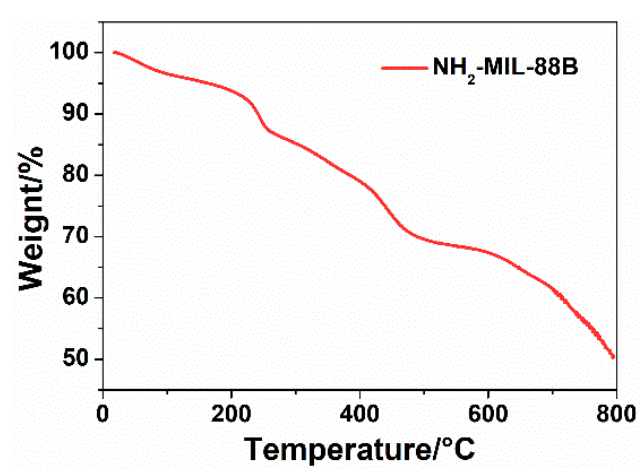

Figure S3. TGA thermogram of $\mathrm{NH}_{2}-\mathrm{MIL}-88 \mathrm{~B}$. 

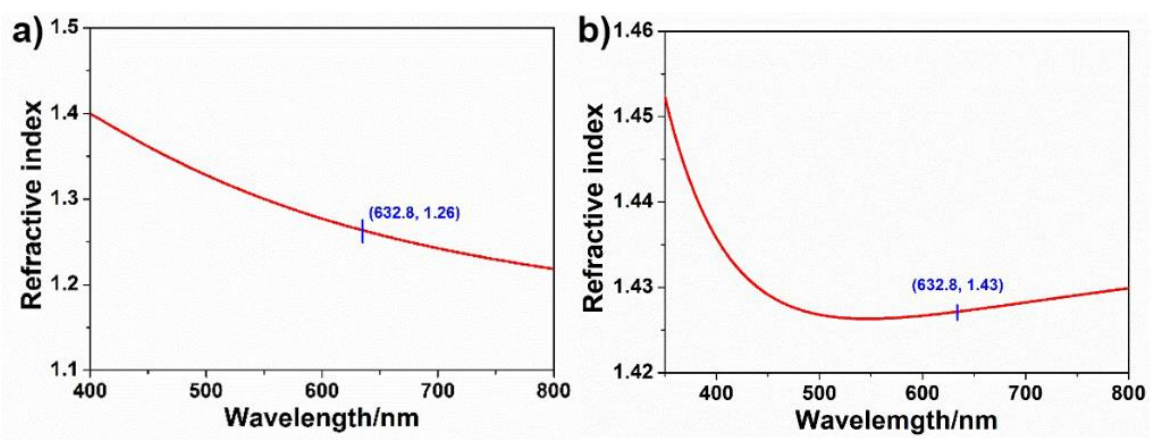

Figure S4. Refractive indexes of a) $\mathrm{NH}_{2}-\mathrm{MIL}-88 \mathrm{~B}$ and b) $\mathrm{P}(\mathrm{St}-\mathrm{AA})$ films.

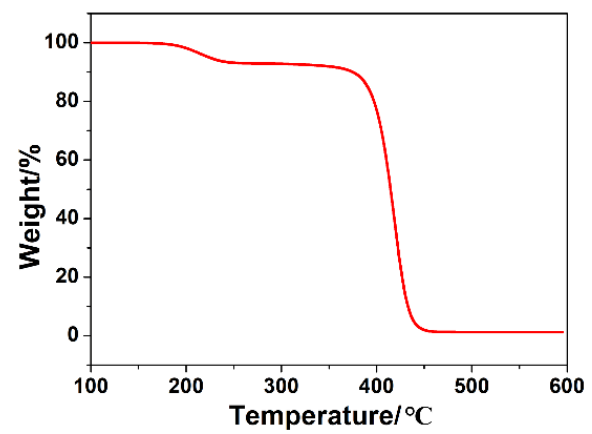

Figure S5. TGA thermogram of $\mathrm{P}($ St-AA).

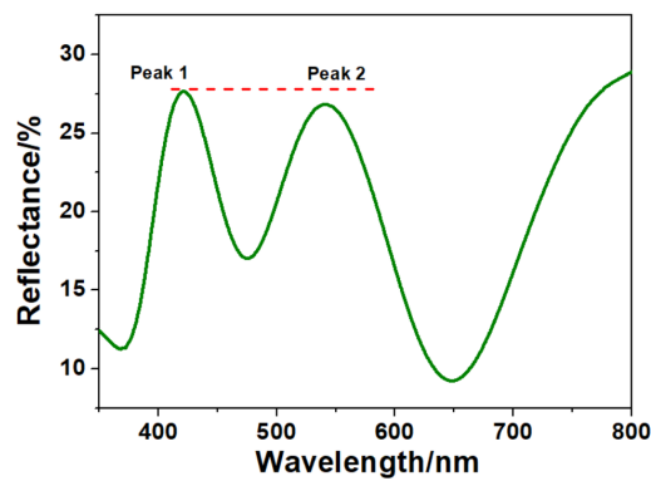

Figure S6. Reflection spectrum of the prepared MOF based PC sensor. The reflectivity of peak 2 which is the stopband is lower than that of peak 1.

Equation S1. The first-order reflection wavelength of a 1DPC can be predicted by Bragg's law:

$$
\lambda_{\max }=2\left(n_{l} d_{l}+n_{h} d_{h}\right)
$$

$\lambda_{\max }$ is the position of the first-order refraction wavelength, $d_{h}$ and $d_{l}$ are the thickness of the high- and low-refractive-index regions, $\mathrm{n}_{\mathrm{h}}$ and $\mathrm{n}_{\mathrm{l}}$ are the refractive indexes of the high- and low-index regions, respectively. 


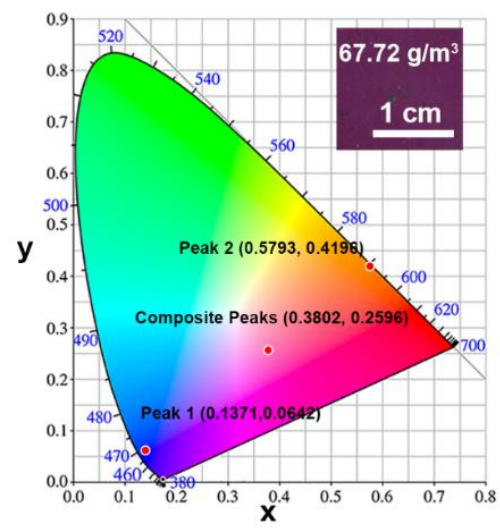

Figure S7. CIE 1931 chromaticity coordinates and photograph of the sensor when exposed to toluene vapor of $67.72 \mathrm{~g} / \mathrm{m}^{3}$.
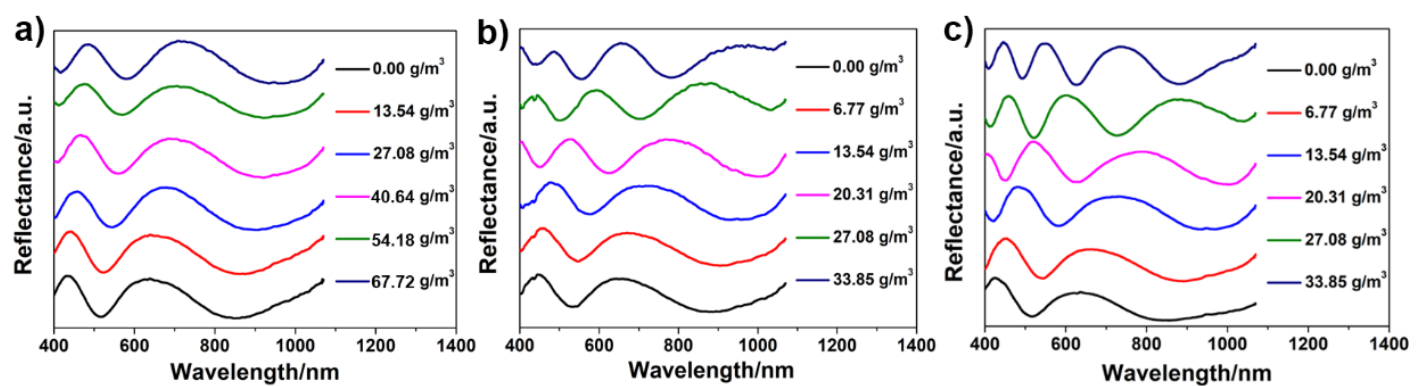

Figure S8. Reflectance spectra of the PC sensor when exposed to a) benzene, b) ethylbenzene and c) xylene vapors with different concentrations.
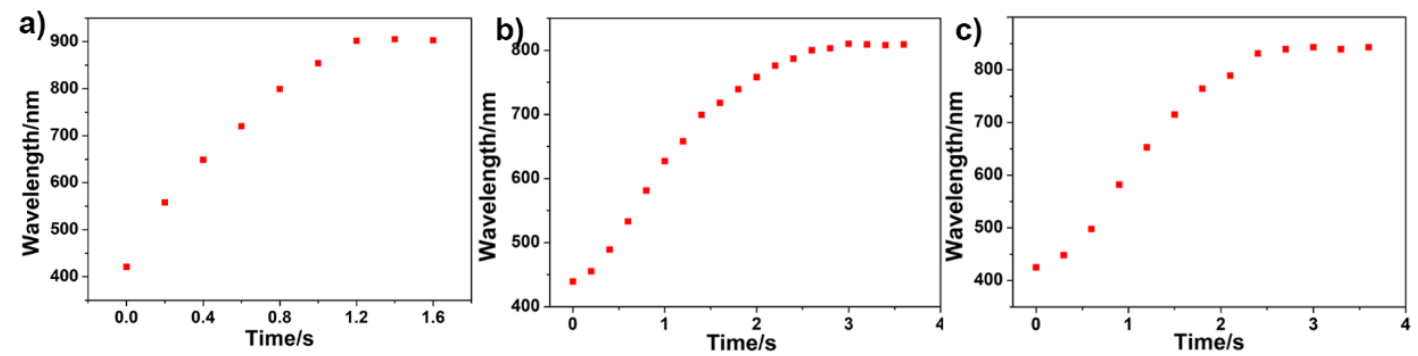

Figure S9. Response time of the sensor to saturated a) benzene, b) ethylbenzene and c) xylene vapors. 

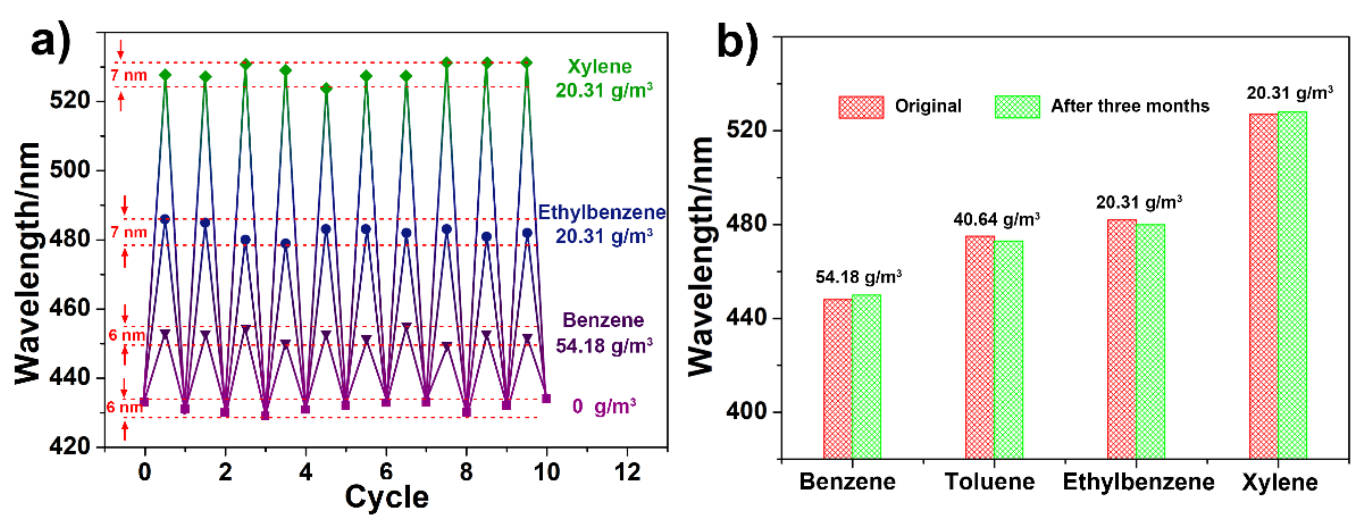

Figure S10. a) Recycle detection test of the sensor in vapors of benzene $\left(54.18 \mathrm{~g} / \mathrm{m}^{3}\right)$, ethylbenzene $\left(20.31 \mathrm{~g} / \mathrm{m}^{3}\right)$ and xylene $\left(20.31 \mathrm{~g} / \mathrm{m}^{3}\right)$, b) the maximum reflection wavelengths of the PC sensor when exposed to benzene $\left(54.18 \mathrm{~g} / \mathrm{m}^{3}\right)$, toluene $(40.64$ $\left.\mathrm{g} / \mathrm{m}^{3}\right)$, ethylbenzene $\left(20.31 \mathrm{~g} / \mathrm{m}^{3}\right)$ and xylene $\left(20.31 \mathrm{~g} / \mathrm{m}^{3}\right)$ before and after three-month storage.

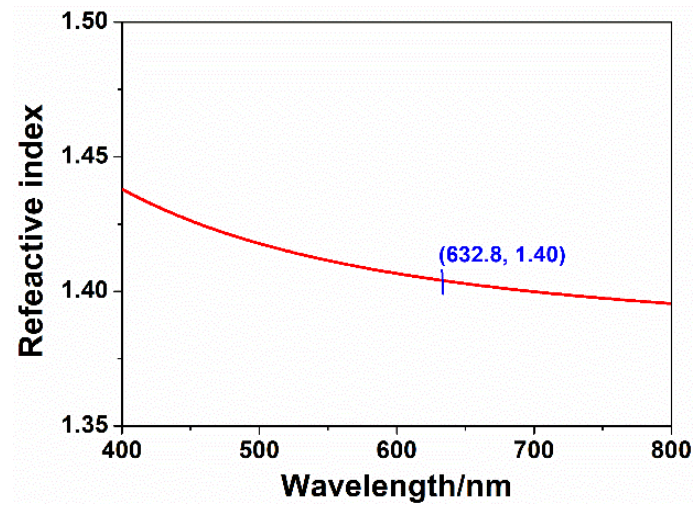

Figure S11. Refractive index of a $\mathrm{SiO}_{2}$ film.

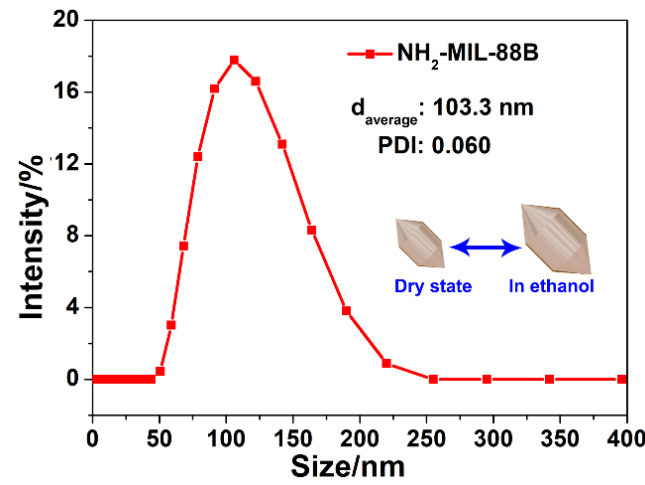

Figure S12. Particle size distribution (in ethanol) of the as-synthesized $\mathrm{NH}_{2}-\mathrm{MIL}-88 \mathrm{~B}$ nanoparticles. 
Table S1. Detection limits comparison between MOF- and $\mathrm{SiO}_{2}$-based PC sensors

\begin{tabular}{ccccc}
\hline & $\begin{array}{c}\text { Benzene } \\
\left(\mathrm{g} \cdot \mathrm{m}^{-3} / \mathrm{ppm}\right)\end{array}$ & $\begin{array}{c}\text { Toluene } \\
\left(\mathrm{g} \cdot \mathrm{m}^{-3} / \mathrm{ppm}\right)\end{array}$ & $\begin{array}{c}\text { Ethylbenzene } \\
\left(\mathrm{g} \cdot \mathrm{m}^{-3} / \mathrm{ppm}\right)\end{array}$ & $\begin{array}{c}\text { Xylene } \\
\left(\mathrm{g} \cdot \mathrm{m}^{-3} / \mathrm{ppm}\right)\end{array}$ \\
\hline MOF-based & $3.70 / 1062.87$ & $0.87 / 211.50$ & $0.42 / 88.62$ & $0.22 / 46.20$ \\
$\mathrm{SiO}_{2}$-based & $5.56 / 1597.18$ & $1.28 / 311.17$ & $1.08 / 228.22$ & $0.59 / 123.90$ \\
\hline
\end{tabular}

Equation S2. The maximum Bragg peak intensity of photonic stopband is given by the following expression:

$$
\mathrm{R}=\left(\frac{1-Y}{1+Y}\right)^{2} \times 100 \%, \quad Y=\left(\frac{n_{h}}{n_{l}}\right)^{N-1} \frac{n_{h}^{2}}{n_{s}}
$$

$\mathrm{n}_{\mathrm{s}}$ is the refractive index of the substrate, $\mathrm{n}_{\mathrm{h}}$ and $\mathrm{n}_{\mathrm{l}}$ are the refractive indexes of the highand low-index regions, respectively, $\mathrm{N}$ is the number of periods of the 1DPCs.

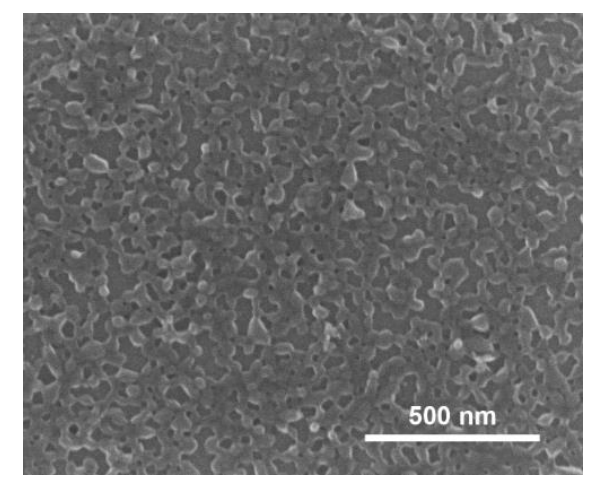

Figure S13. SEM image of the MOF film that was assembled by spin-coating $\mathrm{NH}_{2}-$ MIL-88B nanoparticle dispersion.

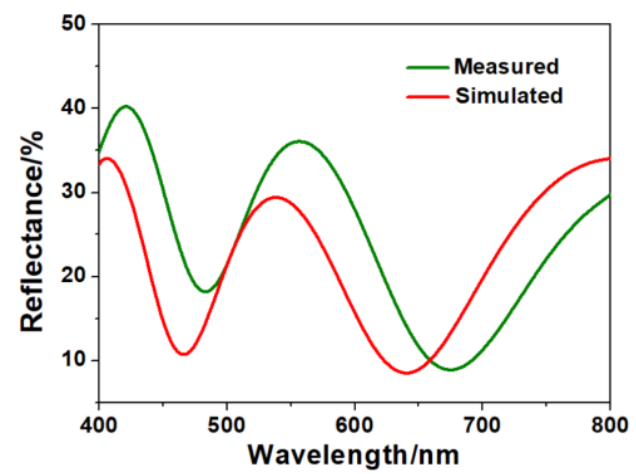

Figure S14. Measured and simulated reflection spectra of the $\mathrm{SiO}_{2} / \mathrm{P}(\mathrm{St}-\mathrm{AA})$ threestack 1DPC. 
Table S2. Simulation parameters of the PC sensors with different refractive index of upper layer (for Figure 5b).

\begin{tabular}{ccccccc}
\hline $\mathrm{n}_{\mathrm{u}}$ & $\mathrm{n}_{\mathrm{s}}$ & $\mathrm{n}_{\mathrm{l}}$ & $\mathrm{d}_{\mathrm{u}} / \mathrm{nm}$ & $\mathrm{d}_{\mathrm{l}} / \mathrm{nm}$ & $\mathrm{N}$ & $\lambda_{\max } / \mathrm{nm}$ \\
\hline 1.2 & 3.8 & 1.43 & 65 & 120 & 3 & 499.2 \\
1.3 & 3.8 & 1.43 & 65 & 120 & 3 & 512.2 \\
1.4 & 3.8 & 1.43 & 65 & 120 & 3 & 525.2 \\
1.5 & 3.8 & 1.43 & 65 & 120 & 3 & 538.2 \\
1.6 & 3.8 & 1.43 & 65 & 120 & 3 & 551.2 \\
1.7 & 3.8 & 1.43 & 65 & 120 & 3 & 564.2 \\
\hline
\end{tabular}

$n_{s}, n_{u}$ and $n_{l}$ are the refractive index of substrate, upper and lower layer; $d_{u}$ and $d_{1}$ are the thickness of upper and lower layer; $\mathrm{N}$ is the stack number; $\lambda_{\max }$ is the maximum reflectance wavelength. The $\lambda_{\max }$ were calculated according to Bragg's law: $\lambda_{\max }=2\left(n_{u} d_{u}+n_{l} d_{l}\right)$.

Owing to the measured photonic stopband position of prepared PC sensor is about $540 \mathrm{~nm}, 1.43$ and 1.32 were determined as the refractive index of polymer and MOF layer when the wavelength was $540 \mathrm{~nm}$ according to Figure S4 and loss sight of the influence of wavelength on the refractive index. 

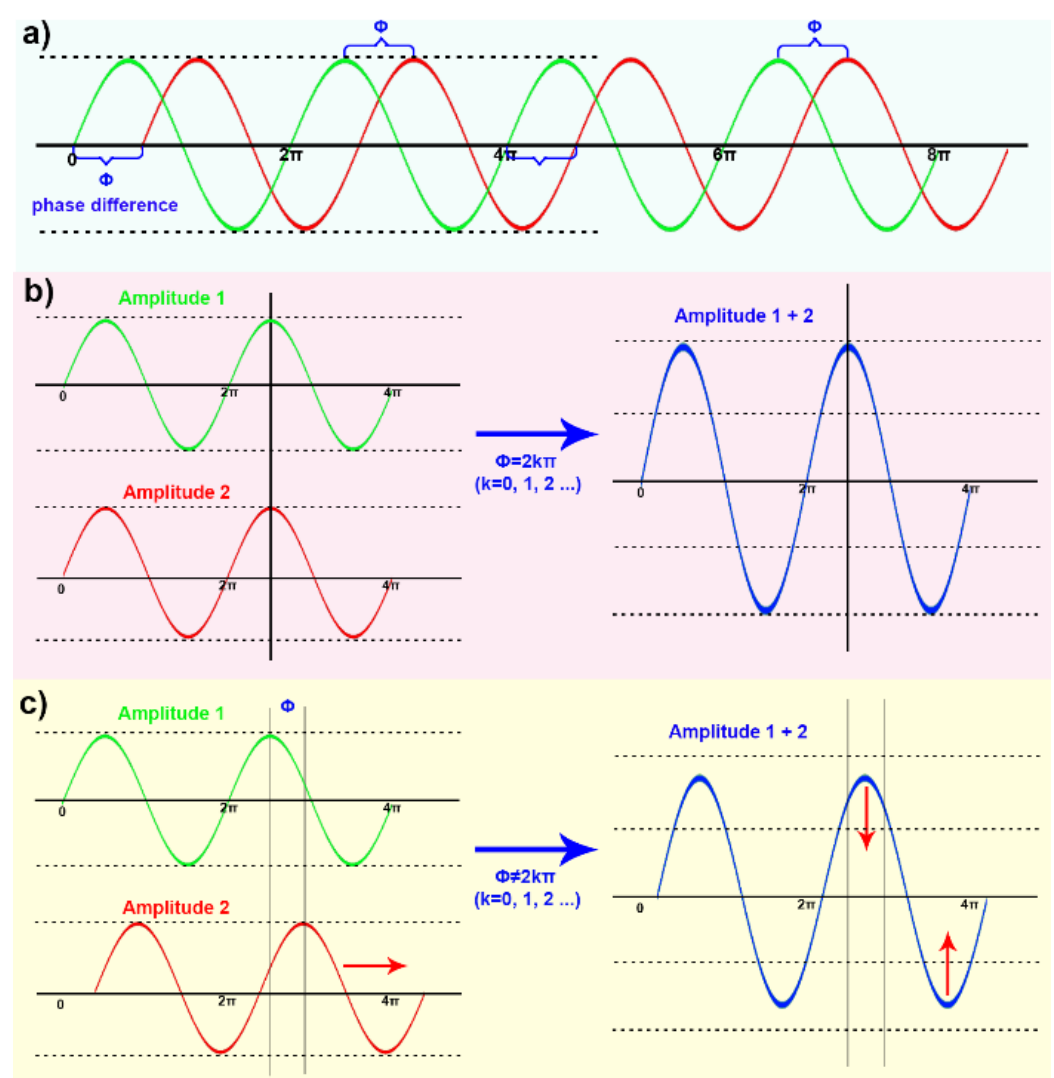

Figure S15. Schematic diagram of a) phase difference $(\Phi)$, b) and c) interference and superposition of two coherent lights. In Figure b, the $\Phi$ between amplitude 1 and 2 is 0 $(\mathrm{k}=0)$, light waves achieve a maximum interference and the photonic stopband of multilayered PC presents a maximum reflectance. In Figure c, with the increase of $\Phi$ from 0 to $\pi(\mathrm{k}=0)$, the amplitude $1+2$ decreases obviously, the reflectance of photonic stopband accordingly is weakened.

Table S3. Simulation parameters of the PC sensors with different refractive indexes of substrates (for Figure 5c)

\begin{tabular}{ccccccc}
\hline $\mathrm{n}_{\mathrm{s}}$ & $\mathrm{n}_{\mathrm{l}}$ & $\mathrm{n}_{\mathrm{u}}$ & $\mathrm{d}_{\mathrm{u}} / \mathrm{nm}$ & $\mathrm{d}_{\mathrm{l}} / \mathrm{nm}$ & $\mathrm{N}$ & $\lambda_{\max } / \mathrm{nm}$ \\
\hline 1.5 & 1.43 & 1.32 & 65 & 120 & 3 & 514.8 \\
2.0 & 1.43 & 1.32 & 65 & 120 & 3 & 514.8 \\
2.5 & 1.43 & 1.32 & 65 & 120 & 3 & 514.8 \\
3.0 & 1.43 & 1.32 & 65 & 120 & 3 & 514.8 \\
3.5 & 1.43 & 1.32 & 65 & 120 & 3 & 514.8 \\
4.0 & 1.43 & 1.32 & 65 & 120 & 3 & 514.8 \\
\hline
\end{tabular}


Table S4. Simulation parameters of the PC sensors with different refractive index es of lower layers (for Figure 5d)

\begin{tabular}{ccccccc}
\hline $\mathrm{n}_{\mathrm{s}}$ & $\mathrm{n}_{\mathrm{l}}$ & $\mathrm{n}_{\mathrm{u}}$ & $\mathrm{d}_{\mathrm{u}} / \mathrm{nm}$ & $\mathrm{d}_{\mathrm{l}} / \mathrm{nm}$ & $\mathrm{N}$ & $\lambda_{\max } / \mathrm{nm}$ \\
\hline 1.5 & 1.43 & 1.32 & 65 & 120 & $3,10,20,30,40,50$ & 514.8 \\
2.0 & 1.43 & 1.32 & 65 & 120 & $3,10,20,30,40,50$ & 514.8 \\
2.5 & 1.43 & 1.32 & 65 & 120 & $3,10,20,30,40,50$ & 514.8 \\
3.0 & 1.43 & 1.32 & 65 & 120 & $3,10,20,30,40,50$ & 514.8 \\
4.5 & 1.43 & 1.32 & 65 & 120 & $3,10,20,30,40,50$ & 514.8 \\
\hline
\end{tabular}

a)

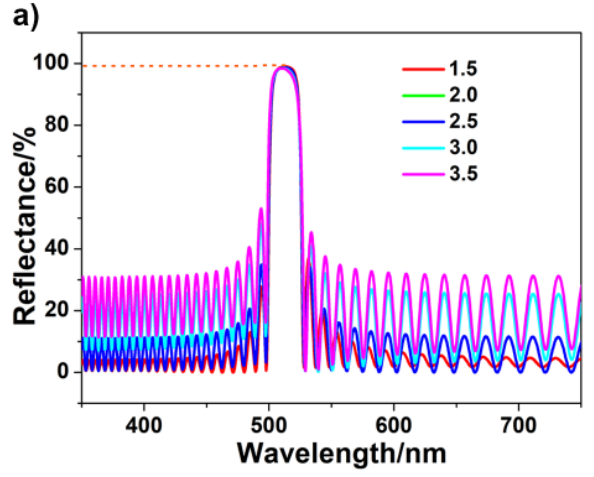

b)

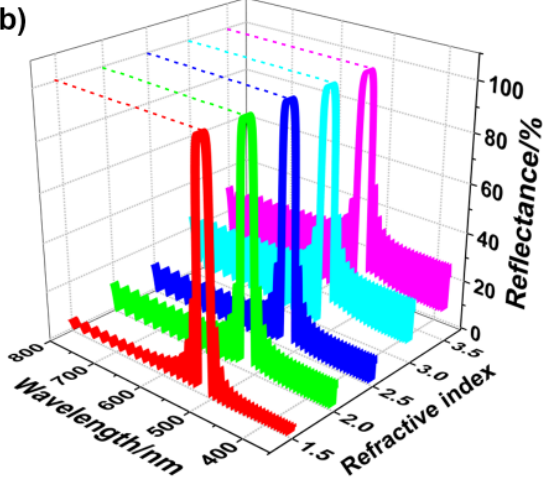

Figure S16. Simulated a) two-dimensional and b) three-dimensional reflection spectra of 50-stack PCs with different refractive indexes of substrates.

Table S5. Simulation parameters of the PC sensors with different refractive indexes of the upper layers (for Figure S17)

\begin{tabular}{ccccccc}
\hline $\mathrm{n}_{\mathrm{u}}$ & $\mathrm{n}_{\mathrm{s}}$ & $\mathrm{n}_{\mathrm{l}}$ & $\mathrm{d}_{\mathrm{u}} / \mathrm{nm}$ & $\mathrm{d}_{\mathrm{l}} / \mathrm{nm}$ & $\mathrm{N}$ & $\lambda_{\max } / \mathrm{nm}$ \\
\hline 1.2 & 3.8 & 1.43 & 65 & 120 & 50 & 499.2 \\
1.3 & 3.8 & 1.43 & 65 & 120 & 50 & 512.2 \\
1.4 & 3.8 & 1.43 & 65 & 120 & 50 & 525.2 \\
1.5 & 3.8 & 1.43 & 65 & 120 & 50 & 538.2 \\
1.6 & 3.8 & 1.43 & 65 & 120 & 50 & 551.2 \\
1.7 & 3.8 & 1.43 & 65 & 120 & 50 & 564.2 \\
\hline
\end{tabular}




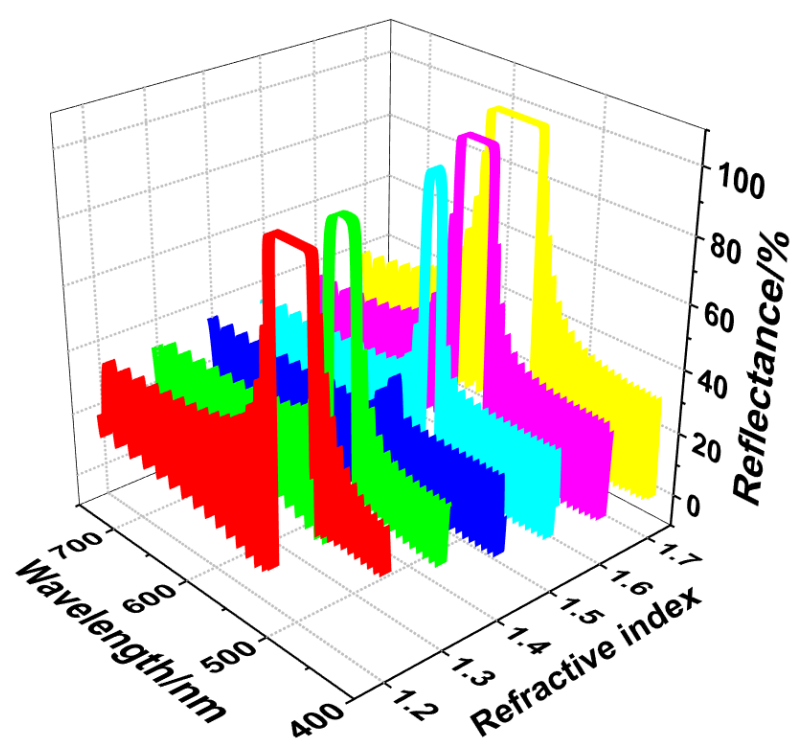

Figure S17. Simulated three-dimensional reflection spectra of 50-stack PCs with different refractive indexes of the upper layers.

Equation S3. Bandwidth (full width at half maximum) is expressed in frequency terms by the following equation:

$$
\Delta \omega=\frac{4 \omega_{\max }}{\pi} \sin ^{-1}\left(\frac{\left|n_{l}-n_{u}\right|}{n_{l}+n_{u}}\right)
$$

where $\omega_{\max }=2 \pi c / \lambda_{\max }$, with $\mathrm{c}$ being the speed of light in a vacuum, $\mathrm{n}_{\mathrm{u}}$ and $\mathrm{n}_{\mathrm{l}}$ are the refractive indexes of the upper and lower layers. 